\title{
Integrating Wind And Solar With Hydrogen Producing Fuel Cells
}

\author{
K. Hemmes ${ }^{\mathrm{a}}$ \\ ${ }^{a}$ Department of Technology, Policy and Management, Delft University of Technology, \\ Delft, NL-2628 BX, The Netherlands
}

The conversion of a surplus of wind energy into hydrogen by means of electrolysis is an often proposed solution for the fluctuating electricity supply from wind energy. In this paper a patented alternative is proposed consisting of the integration of wind turbines with internal reforming fuel cells, capable of coproducing hydrogen and electricity from natural gas. Storage of hydrogen is not absolutely necessary in this concept, since the naturally available energy storage capacity of the gas field can be effectively used. The flexibility of a fuel cell to vary electric output and/or simultaneously produce hydrogen from natural gas can be used advantagely in an integrated wind turbine fuel cell configuration. Flow sheet calculations have shown that the change in hydrogen output can be more than three times the increase in electric input from wind energy at constant natural gas input and constant total electric power output, resulting in an apparent conversion efficiency of more than $300 \%$.

\section{Introduction}

It is well known that renewable energy sources, especially wind energy and solar energy have a fluctuating character, which is difficult to match with practical demand. There is a limit to what the electric grid can accommodate. Also a surplus of wind energy would require the part load operation of conventional central power plants, which will make them less efficient and their operation less economic. The conversion of the surplus of wind energy into hydrogen by means of electrolysis is the standard solution for this problem. Hydrogen can be stored and converted back into electricity by a fuel cell when demand is high and there is no or little supply of renewable electricity from solar or wind. However, this solution suffers from efficiency losses in all the conversion steps and in the storage of hydrogen. Moreover the cost of the system is high, while its utilization factor i.e. the percentage of the time that it is used is low.

The alternative can be found in the possibility of an internal reforming fuel cell to coproduce hydrogen and electricity. This can be used beneficially to integrate wind energy into the electric grid. A peak in electric power from wind energy can be compensated by an equal decrease in electricity production from the fuel cell. At constant natural gas input this will lead to lower fuel utilization; thus more hydrogen (and $\mathrm{CO}$ ) will exit the fuel cell unreacted. A decrease in electric power output from the fuel cell is more than compensated by an increase in hydrogen output. Calculations have shown that the change in hydrogen output can be more than three times the increase in electric input from wind energy. The words 'change' and 'increase' have been put in italics to indicate a deviation from the standard operation point. Therefore we can obtain an apparent conversion efficiency of more than $300 \%$. What happens on the whole is that the system becomes 
more efficient in the sense that it produces less waste heat and more energy in terms of hydrogen and electric power.

This system is an example of a more general concept called 'multisource multiproduct or MSMP concept [1-3]. Historically, energy conversion was seen as a onedimensional system, in the sense that one form of energy was converted into another form. By-products of the conversions such as heat were disregarded and/or treated as waste. Cogeneration is a first step towards system improvement since the 'waste heat' is recovered and used as a valuable product. Tri-generation systems, which take the concept even further, are proposed for the simultaneous production of chemicals, power and heat, and are integrated into larger systems, such as chemical plants, to achieve increased overall performance. In these systems electricity may just be a by-product. However, coand tri-generation systems are still characterized by one energy input source. In this paper we further extend this concept and explore the potential role of multi-source multiproduct (MSMP) systems and will work out the example of the integration of renewable electricity from wind or solar with an internal reforming fuel cell fed by natural gas.

\section{The concept}

A. Flexible co-production of hydrogen and power by an internal reforming fuel cell.

In earlier publications we have described the flexible co-production of hydrogen and electric power by an internal reforming fuel cell [4].

Internal reforming fuel cells are well-known. One effectively applies the principle of heat integration by using the (waste) heat dissipated in the fuel cell for the endothermic reforming reaction of natural gas with steam to hydrogen, carbon monoxide and carbon dioxide according to the reactions:

$$
\begin{array}{lll}
\mathrm{CH}_{4}+\mathrm{H}_{2} \mathrm{O} \Leftrightarrow 3 \mathrm{H}_{2}+\mathrm{CO} & \text { (reforming reaction) } \\
\mathrm{CO}+\mathrm{H}_{2} \mathrm{O} \Leftrightarrow \mathrm{H}_{2}+\mathrm{CO}_{2} & \text { (shift reaction) }
\end{array}
$$

Equilibrium is determined by temperature and pressure, but in general the amounts of hydrogen and $\mathrm{CO}$ produced are about equal. Inside the fuel cell the reactions are shifted to the right hand side by the electrochemical reaction of hydrogen into steam at the anode of the fuel cell. For the SOFC and MCFC these reactions are respectively:

$$
\begin{array}{lll}
\mathrm{H}_{2}+\mathrm{O}^{2-} & \Leftrightarrow \mathrm{H}_{2} \mathrm{O}+2 \mathrm{e}^{-} & (\mathrm{SOFC}) \\
\mathrm{H}_{2}+\mathrm{CO}_{3}{ }^{2-} \Leftrightarrow \mathrm{H}_{2} \mathrm{O}+\mathrm{CO}_{2}+2 \mathrm{e}^{-} & \text {(MCFC) }
\end{array}
$$

In standard fuel cell operation one tries to convert as much of the fuel as possible. Since $100 \%$ utilization is theoretically impossible for presently used high temperature internal reforming fuel cells (IR-SOFC and IR-MCFC) an optimum for the fuel utilization is practically found to be around $90 \%$ in standard operation.

The reforming reaction consumes a large fraction of the dissipated heat in the fuel cell thereby minimizing the need for cooling and increasing the overall system efficiency. However, in standard operation still a surplus of heat is available in internal reforming fuel cells. This allows the fuel cell to reform more natural gas into hydrogen than needed for its own electrochemical consumption. Therefore the fuel cell is able to produce hydrogen as well as electricity. Moreover by increasing the electric load and thus increasing current density the electric power output can be increased, albeit at the 
expense of decreasing electric efficiency of the fuel cell. In other words more heat is produced that however, can be converted into hydrogen as well, in the endothermic reforming reaction by introducing more natural gas into the fuel cell. Flow sheet calculations have shown that the anode off-gas thus still may contain a lot of hydrogen and $\mathrm{CO}$ [4]. We note that $\mathrm{CO}$ can be shifted in a separate reactor to hydrogen according to the almost thermo-neutral water-gas shift reaction (2). For the sake of simplicity we will therefore treat $\mathrm{CO}$ as being more or less equivalent to hydrogen in this paper.

Fuel cell operation is essentially controlled by two 'knobs': a) the input flow of natural gas and b) the value of the electric load. Various combinations of the two yield many operation modes certainly if one regards hydrogen to be a useful product.

Previous fuel cell modeling work has shown that the performance of a fuel cell can be described by the cell voltage $V_{\text {cell }}$ as a function of current density (determined by the external electric load) and fuel utilization (determined by the ratio between current density and fuel input flow). It has been shown that $[5 ; 6]$ :

$$
\mathrm{V}_{\text {cell }}=\mathrm{OCV}-i \cdot \mathrm{r}-1 / 2 \alpha \mathrm{u}_{\mathrm{f}}
$$

The Open Cell Voltage OCV is determined by temperature, pressure and the gas compositions at the anode and cathode inlets. All internal losses are represented in this model by a quasi-ohmic resistance ' $r$ '. The term $1 / 2 \alpha u_{f}$ represents the so-called Nernst losses caused by the decrease in the partial pressure of the reactants when going from inlet to outlet of the fuel cell. The factor $\alpha$ is about $200 \mathrm{mV}$ for the MCFC and SOFC, while the OCV is approximately 1 Volt. The i.r losses are typically in the order of $100 \mathrm{mV}$. So in standard operation conditions with a fuel utilization of $90-95 \%$ the Nernst loss is about equal to the second quasi-ohmic loss term. Reducing fuel utilization will thus significantly decrease the last loss term in eq. (5) and thus decrease overall losses. The cell voltage $\mathrm{V}_{\text {cell }}$ and fuel cell efficiency are comparably increased. Calculations have shown that fuel utilization can be as low as $60 \%$. This means that $40 \%$ of the natural gas heating value is still contained in the hydrogen and CO leaving the fuel cell anode. Fuel utilization can be reduced by increasing the fuel input and/or decreasing current density. With respect to standard operation the first option effectively uses the surplus heat to produce hydrogen while as a positive side effect it increases cell voltage and hence electric power output (at constant current density).

Keeping the fuel input constant and decreasing current density will increase cell voltage by lowering both loss terms in equation (5). The power output $\mathrm{P}=\mathrm{i}$. $\mathrm{V}_{\text {cell }}$ experiences two opposite changes. The decreasing current density is partially compensated by an increase in cell voltage. So for a relatively small decrease in the electric power output, calculations have shown that at constant fuel input an increase in hydrogen/CO production of more than three times the decrease in electric power output can be obtained. These internal reforming fuel cell characteristics are effectively used in the combination with renewable energy as will be explained in the next section. We note that for a fair comparison it is important to keep fuel input constant. However, we like to emphasize that off-design operation is possible and might be more beneficial. One might for example double the current density. This is normally not done because fuel cell efficiency will decrease too much due to the doubling of i.r losses. However, if we simultaneously decrease fuel utilization by a significant increase in natural gas input, the increased losses are partially compensated by a smaller Nernst loss. Electric power output $\left(\mathrm{P}=\mathrm{i} . \mathrm{V}_{\text {cell }}\right)$ is almost doubled and in addition a much large production of hydrogen is accomplished that can compensate the loss in electric efficiency in economic terms. In a 
previous paper we have presented detailed results of flow sheet modeling of an IR-SOFC system that confirmed the analysis and predictions above, that are solely based on the simple analytical fuel cell model by F.R.A.M. Standaert et al. [5;6].A plot of the hydrogen and power outputs calculated using the flow sheet program 'Cycle Tempo' is shown in figure 1a) together with a plot of the efficiencies in figure 1b). [4]
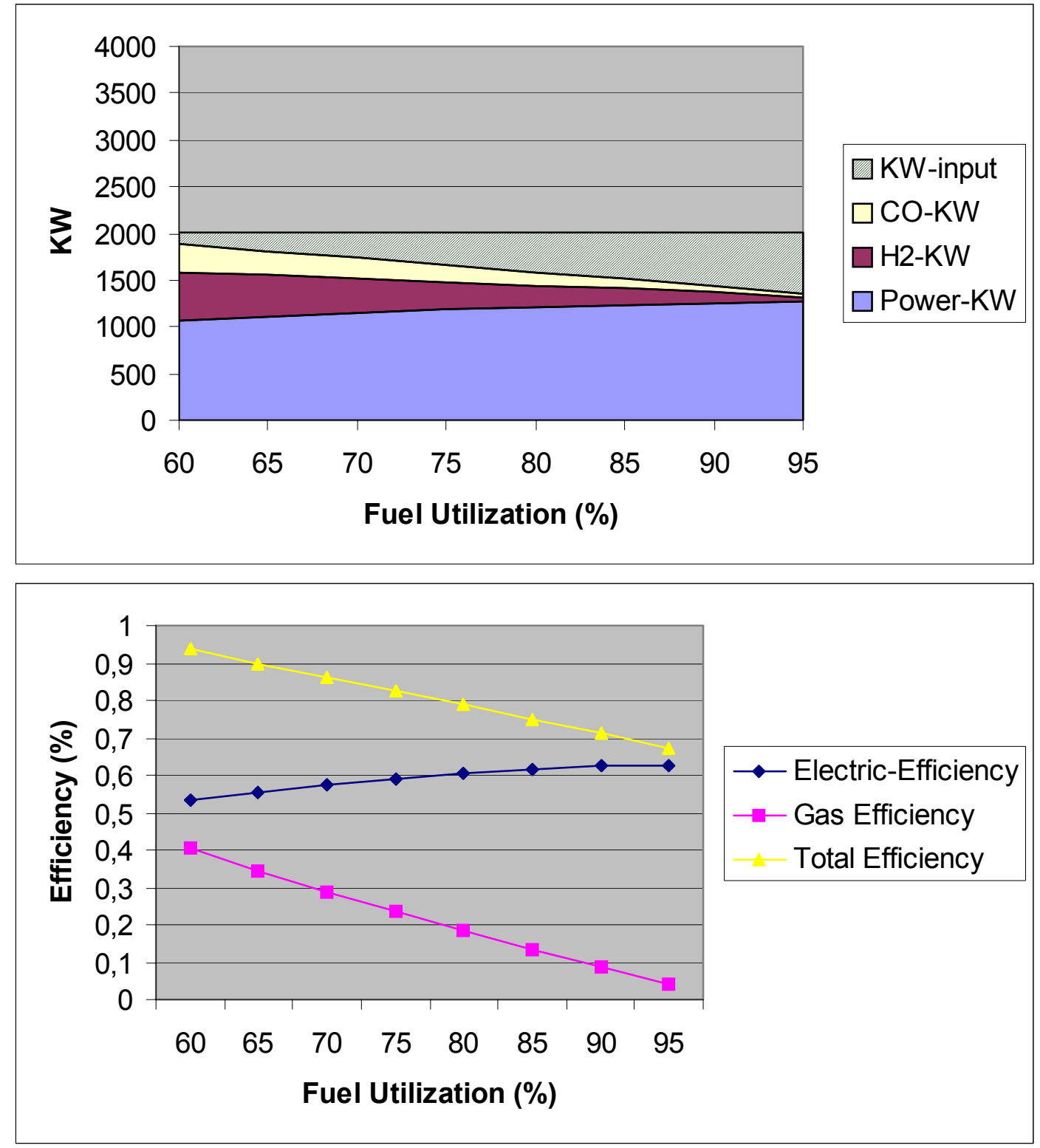

Figure 1 a) Plot of the fuel cell input and output at constant natural gas input. b) Plot of the electric and gas efficiencies, all as a function of fuel utilization.

The electric efficiency has its usual definition, while the gas efficiency is defined as the ratio of the power output in the form of $\mathrm{CO}$ plus hydrogen relative to the natural gas power input. Following the definitions, there is a reverse relation between the fuel utilization $u_{\mathrm{f}}$ and the gas efficiency $\eta_{\mathrm{g}}$ :

$$
\mathrm{u}_{\mathrm{f}}=1-\eta_{\mathrm{g}} \quad \text { or } \quad \eta_{\mathrm{g}}=1-\mathrm{u}_{\mathrm{f}}
$$


From Figure 1b) we can see that the electric efficiency as calculated by flow sheet modeling approaches a straight-line.

$$
\eta_{\mathrm{e}}=0.29 \mathrm{u}_{\mathrm{f}}+0.35
$$

The figures clearly show that a decrease in electric power output is more than compensated by an increase in hydrogen and $\mathrm{CO}$ outputs at lower fuel utilization. In other words, the system efficiency defined as the sum of electric and gas power outputs relative to natural gas input has increased at lower fuel utilization. These characteristics are used advantageously in the following section.

B. Integration of fluctuating renewable energy sources with flexible co production of hydrogen and power in a fuel cell

It is well known that renewable energy sources, especially wind energy and solar energy have a fluctuating character, which is difficult to match with practical demand. There is a limit to what the electric grid can accommodate. Also a surplus of wind energy requires conventional central power plants to operate in part load, which will make them somewhat less efficient and their operation less economic because the capacity of the plant and its investments cost is not used to the full extent. As explained above the frequently proposed solution for this problem is the conversion of the surplus of wind energy into hydrogen by means of electrolysis. However, this solution suffers from efficiency losses in all the conversion steps and in the storage of hydrogen. Moreover system costs are high, while it is only utilized in a relative small fraction of time.

Here an alternative is proposed in the form of the multi source multi product system of figure 2. In this figure, the possibility of an internal reforming fuel cell to co-produce hydrogen and electricity as explained above is used beneficially to integrate wind energy into the electric grid. As an example the natural gas input and the electric output are kept constant. Therefore, a peak in electric power from wind energy, as indicated in figure 2 by a block function in time, is compensated by an equal decrease in electricity production from the fuel cell.

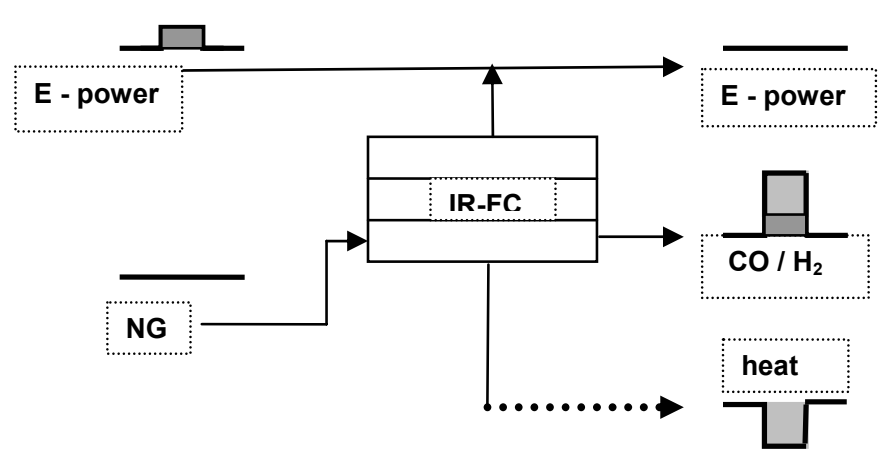

Figure 2. Integrated energy system using the flexible co production of hydrogen and power of an internal reforming fuel cell to compensate a fluctuating supply of renewable energy.

As explained above the decrease in power output of the fuel cell at constant natural gas input will lead to lower fuel utilization; thus more hydrogen (and $\mathrm{CO}$ ) will exit the fuel cell. As shown in figure 1a) decrease in electric power output is more than 
compensated by an increase in hydrogen output. Calculations have shown that the change in hydrogen output can be more than three times the increase in electric input from wind energy [7]. Directly relating this increased output of hydrogen to the increased inputs of electricity would yield a conversion efficiency of more than $300 \%$. Among other things, it shows that using MSMP systems requires careful definition and application of efficiencies. However, if we compare this MSMP system with the conventionally proposed solution undeniably more than three times as much hydrogen is produced from a surplus of electric power. This is indicated in Figure 2 by the block functions in time. Obviously the first law of thermodynamics is not violated and the strong increase in hydrogen output is compensated by a decrease in output of (waste) heat reflecting the higher efficiency of the system at lower fuel utilization as already shown in Figure 1 and explained in section A above.

\section{Evaluation of the integrated fuel cell wind turbine system.}

A preliminary study has been performed as part of the graduation work of G. Bos in order to analyze, evaluate and compare different combinations of wind turbines and internal reforming fuel cells to better understand the possibilities and advantages of certain options. In this paper, we will highlight critical issues in a proper comparison between options.

The concept as described above using the fuel cell characteristics of figure 1 is just one possibility of operating the fuel cell and wind turbine system. As explained above the operation point of the fuel cell is the standard operation point for high efficient production of electricity. Lowering the electric load will lead to hydrogen production at constant natural gas input. This is the preferred way to operate the fuel cell in combination with a wind turbine, when high efficiency is the ultimate goal. However, one could also argue that one should compare the here proposed MSMP system with the standalone case of a hydrogen producing, internal reforming fuel cell as the new standard operation condition. After all, when there is a need for hydrogen and power, a standalone internal reforming fuel cell might be very suitable, since it is a very flexible and efficient co-production unit. Of course, the cases to compare the newly proposed MSMP system with should also include; the standalone wind turbine delivering to the electric grid and the wind turbine/electrolysis/hydrogen storage/fuel cell system. In summary we can distinguish the following cases:

Case 1: standalone wind turbine

Case 2: standalone IR-FC with flexible co production of hydrogen and power

Case 3: wind turbine + fuel cell producing only power

Case 4: conventional solution: wind turbine/electrolysis/hydrogen storage/fuel cell

Case 5: 'super wind': wind turbine + IR-FC producing hydrogen + power

It is noted that case 3 should be added to acknowledge the fact that the fuel cell can vary power output without producing hydrogen, since hydrogen will not always be needed. By adjusting the fuel input and electric load the required power output can be obtained. In this way also a stable and continuous power output from the fuel cell - wind turbine combination can be obtained. The fuel cell does not need to be an internal reforming fuel cell than, but can be any fuel cell system with any fuel as long as it is able to operate dynamically. Examples of suitable fuel cells for case 3 are PAFC and polymer fuel cell. 
An interesting question is also, if it is really necessary to apply an internal reforming fuel cell in case 2, or that it is also possible to use external reforming? The production of hydrogen can very well take place in an external reforming unit. However, the wellknown benefit of internal reforming is the heat integration of an exothermic and an endothermic processes in one device. In external reforming a lot of heat has to be transfered by suitable means from the fuel cell to the reformer. In general however, large (exergy) losses occur in heat transfer. Operating the fuel cell in high-power mode at high current density, as would be very well possible in the internal reforming fuel cell, would increase the losses in heat transfer. Moreover, hydrogen production at low fuel utilization consumes the surplus heat available in the fuel cell and reduces the need for external cooling. Normally this cooling is provided by a large cathode flow consuming auxiliary power for the blowers. At low fuel utilization (i.e. hydrogen production) the auxiliary power needed for cooling is reduced. All these effects are taken into account in the Cycle Tempo flow sheet calculations. So apart from the increased heat transfer losses, using external reforming would also increase the necessary auxiliary power. Therefore, the concept is preferably applied using an internal reforming fuel cell.

When comparing the various cases the boundary conditions should be clear, and each case should be operated in a comparable and optimized mode. Optimization however, is quite complicated when taking into account actual wind profiles and power output fluctuations. Also, the optimization goal might be different for different stakeholders. Some want to optimize economic performance, others want to minimize $\mathrm{CO}_{2}$ emissions or increase efficiency. Work is on the way to provide the necessary mathematical algorithms to do the detailed and proper optimization under exact boundary conditions [2]. When performing an economic analysis, of course price information is very essential. Since fuel cells are still in the development phase and the prototypes and the fuel cell systems on demonstration sites are still expensive, a realistic analysis for a situation in the not too far future is difficult, if not speculative. Yet prices are expected to decrease significantly. Apart from capital investments, also the price per kilowatt hour electricity and the price for hydrogen are subject to change. An additional complication arises when the government is frequently changing its subsidy and tax reduction policy on renewable energy as holds for the Netherlands. When comparing a standalone wind turbine with a fuel cell turbine combination it is essential to note the difference between the $\mathrm{kWh}$ prize for fluctuating and uncertain power from the wind turbine and the $\mathrm{kWh}$ prize for stabilized and continuous power supply as from the wind turbine - fuel cell combination. According to our information presently the difference is only one Euro cent. This is quite a small margin to compensate for the additional capital investments in a fuel cell. In this case, the profitability has to be derived from the hydrogen production.

\section{Discussion and Conclusions}

Although the results as presented are a significant improvement with respect to present operation of fuel cells and the proposed solution of hydrogen production and storage it must be noted that the system as presented above would require a large total capacity of fuel cells since one uses the fuel cell's flexibility in operation to compensate large fluctuations in wind energy from -in principle at least- zero to full power. Therefore the fuel cell standard capacity must be significantly larger than that of the wind turbine. Presently the integration of wind energy in the electric grid causes problems especially for the large scale wind farms. Therefore this would require the fuel cells to be of even 
larger capacity than the power rating of these wind parks. This seems far beyond the present state of the art in fuel cell development with its demonstrations on a 1-2 MW scale maximum. On the other hand fuel cells are modular and can be produced in large quantities yielding the required power. Another solution lies within the fuel cell characteristics it self. In our earlier work we also calculated the operation of the fuel cell at high power density[7]. In co production mode this makes sense, because a lower efficiency is compensated by a higher output of hydrogen. The heat dissipated in the fuel cell is internally converted into hydrogen by the reforming reaction. In this mode the same fuel cell can produce twice as much electric power as compared to standard operation. On top of that an almost equal flow of hydrogen (in energy per unit time) at still high overall system efficiency (electricity + hydrogen) is produced. This would make the system economically more viable compared to standard operation and would require less fuel cell modules and thus less capital investment in the integration with wind energy concept.

A further integration is possible with the natural gas grid itself. In natural gas mixing stations sometimes nitrogen is mixed into the gas to lower the caloric value and Wobbe index when needed. In the future possibly also hydrogen will be mixed into the gas network. In the here proposed and discussed systems hydrogen is produced at the anode side of the fuel cell and nitrogen at the cathode side. Although gas separation and cleanup may still be necessary before introduction into the gas network is feasible the concept still offers benefits above conventional ways of producing nitrogen and hydrogen. Because the reforming reaction and hydrogen production consume almost all of the dissipated heat of the fuel cell, the cathode flow does not need to be used for cooling and can be reduced to provide just enough oxygen for the fuel cell. Thereby the oxygen content in the cathode of gas is minimized and the nitrogen content strongly increased to almost $100 \%$. The wide range of integration options are recently filed in a Dutch patent application.[8]

\section{Acknowledgment}

The author would like to acknowledge student Geert Bos of the HAN Hogeschool Arnhem Nijmegen and ir Erik de Nie and Huib Hupkens van der Elst of H2NE (www.H2NE.nl) for their calculations and stimulating discussions.

\section{References}

1. K. Hemmes, J. L. Zachariah, M. Geidl, and G. Andersson. Towards Multi-Source Multi-Product Energy Systems. [Extended abstract in proceedings of $2^{\text {nd }}$ European Hydrogen Energy Conference. November 22nd-25th, 2005 - Zaragoza, Spain]. 2005.

2. M. Geidl and G. Andersson. A modeling and optimization approach for multiple energy carrier power flow. IEEE PES International Conference on Electric Power Engineering (PowerTech), 2005. 2005. St. Petersburg, Russia, IEEE PES. 2005. 
3. M. Geidl and G. Andersson. Optimal power dispatch and conversion in systems with multiple energy carriers. 15th Power Systems Computation Conference (PSCC). 2005. Li'ege, Belgium, 2005. 2005.

4. K. Hemmes, A. Patil, and N. Woudstra. Internal Reforming SOFC System for Flexible Co production of Hydrogen and Power. Proceedings of FUELCELL2005 Third International Conference on Fuel Cell Science, Engineering and Technology May 23-25, 2005, Ypsilanti, Michigan paper\# 74153. 23-5-2005. Ypsilanti, Michigan USA.

5. F. R. A. M. Standaert, K. Hemmes, and N. Woudstra, Journal of Power Sources, 63 (1996) 221-234.

6. K. Hemmes, Fuel Cells; in Modern Aspects of Electrochemistry VOL 37, Kluwer Academic/Plenum Publishers, New York, 2004, Ch. 4.

7. K. Hemmes, A. Patil, and J. L. Zachariah. Flexible co-production of hydrogen and power using fuel cells. Proceedings of the International Gas Research Conference Nov. 2004 Vancouver Canada. 1-10-2004. Vancouver, Canada.

8. K. Hemmes. Systeem en werkwijze voor integratie van duurzame energie en brandstofcel voor het produceren van elektriciteit en waterstof. Nederlandse octrooiaanvrage nr. 1029758. 2006. 17-8-2005. 